\title{
Positive Psychological Interventions for Teachers: a Randomised Placebo-Controlled Field Experiment Investigating the Effects of Workplace-Related Positive Activities
}

\section{Benjamin Dreer ${ }^{1}$ (D)}

Accepted: 29 January 2020 / Published online: 12 February 2020

(C) The Author(s) 2020

\begin{abstract}
A realistic-positive attitude has repeatedly been identified as an important protective factor against school teachers' stress and strain. However, effective programmes fostering teachers' positive emotions, thoughts, and behaviours are still lacking to date. Despite mounting evidence showing their effectiveness, positive psychological interventions have seldom been applied and studied in the work environment of teachers. While initial evidence highlights the potential value of positive interventions for teachers, existing studies have significant shortcomings due to small sample sizes, and limitations in study and intervention designs. This paper documents a placebocontrolled field experiment testing the effects of an online-based positive intervention programme. In total, 309 German school teachers were surveyed at three intervals (preintervention, post-intervention, follow-up). The results show an increase in job satisfaction and teacher engagement that lasts for two weeks post-intervention. Furthermore, long-term decreases in emotional exhaustion were observed. The effects were of a small size. In contrast, significant mean changes were not observed under the placebo condition. The implications and limitations of these findings are discussed.
\end{abstract}

Keywords Positive psychological interventions · Job satisfaction · Teacher engagement · Emotional exhaustion · Teacher well-being

\section{Introduction}

In 2002, the Scottish Executive Education Department commissioned a review of the research literature on teacher stress. Wilson's (2002) comprehensive overview of the

Benjamin Dreer

benjamin.dreer@uni-erfurt.de

1 Erfurt School of Education, University of Erfurt, Nordhäuser Straße 63, D-99089 Erfurt, Germany 
research findings spanning a 10-year period reported that teachers were exposed to jobspecific tasks and conditions that resulted in stress and strain, which in turn could cause psychological and physical illnesses. Interestingly, the general recommendation for coping with stress was for teachers to 'develop realistic, positive attitudes' (p. 7). Almost two decades later, this advice does not appear to have lost any of its value. In fact, the results of several recent studies repeatedly point to a positive attitude as an important protective factor against teachers' daily stress and strain, and their alleged effects (e.g., Andrew et al. 2018; Buonomo et al. 2017; Haydon et al. 2018; Janssen et al. 2008). Although the need has repeatedly been stated (e.g., Gibbs and Miller 2014; McCullough 2015), it has not led to evidence-based and fully evaluated programmes or interventions fostering positive attitudes among either student teachers or in-service teachers (Hwang et al. 2017; McCullough 2015; Necsoi 2018).

Parallel, positive psychology explores the so-called positive activities and their impacts on the happiness and well-being of clinical and non-distressed populations. Based on these findings, interventions have been developed with the aim of promoting happiness and positivity both inside and outside of therapeutic settings. Such positive psychological interventions (PPIs) are defined as 'intentional activities aimed at cultivating positive feelings, positive behaviours, or positive cognition' (Sin and Lyubomirsky 2009, p. 467). They are based on central theoretical concepts of positive psychology, such as gratitude, strengths, optimism, and kindness. A set of PPIs has repeatedly been found to be effective in sustaining increased happiness and well-being, while also sustaining decreased depressive symptoms (Bolier et al. 2013; Seligman et al. 2005; Sin and Lyubomirsky 2009). The latest developments lead to effective selfadministered programmes for everyday usage that are increasingly being offered directly to online users (Bolier and Abello 2014). Despite all these developments, PPIs for the work context are rather scarce, especially for school teachers.

Based on this appraisal, advances in research and practice can be anticipated by designing and studying PPIs, especially for the demanding workplace of teachers. This paper presents a randomised placebo-controlled field experiment that investigates the potential benefits of an online-based intervention programme containing six positive activities for teachers.

\section{Positive Interventions for Teachers}

\subsection{Basic Characteristics and Mechanisms of PPIs}

A growing body of research points to the beneficial effects of PPIs. People performing brief and standardisable positive activities in daily life report longterm increased well-being and happiness and decreased depressive symptoms compared with groups of people who do not engage in such activities (e.g., Lyubomirsky et al. 2005; Parks and Titova 2016; Seligman et al. 2005; Sin and Lyubomirsky 2009). In a meta-analysis, Bolier et al. (2013) showed that PPIs had overall small to moderate effects in pre- and post-intervention comparisons, as well as in intervention and placebo or control group comparisons. The changes appeared to be rather stable, as revealed by follow-up measurements up to 6 months after the interventions. 
Commonly, PPIs consist of brief instructions and descriptions of activities (e.g., 'Count your blessings three times per week'), which are provided to participants, together with additional knowledge presented in books, and in face-to-face or online settings (Parks and Titova 2016). Depending on the approach, positive activities are performed under guidance and supervision or independently. In non-distressed populations, self-administered online interventions are gaining popularity (Parks et al. 2018).

Positive activities are mostly based on one of several domains of positive psychology. Parks and Titova (2016) identified seven main categories: (1) savouring, (2) gratitude, (3) kindness, (4) empathy, (5) optimism, (6) strengths, and (7) meaning. Other sources included (8) hope and (9) mindfulness (see McCullough 2015). Each category appears to have its own subtradition and scientific discourse. When compared, strength-based PPIs reportedly had the most impact on happiness and well-being (McCullough 2015; Seligman et al. 2005). However, PPIs under all the mentioned categories proved effective to some extent (see Parks and Schueller 2014).

Despite their effectiveness, to date, little is known about the psychological mechanisms of PPIs. As pointed out by Nevill (2014), the lack of a theoretical background impedes the full comprehension of how PPIs work. However, some theoretical approaches guide the understanding about the behavioural aspects of PPIs. For example, Lyubomirsky and Layous' (2013) proposed positive-activity model aims to explain the conditions that can contribute to PPIs' effectiveness. The model posits that positive activities influence emotions, thoughts, and behaviours, as well as the fulfilment of basic psychological needs, which in turn leads to a change in well-being. The model also states that engaging in positive activities can directly influence well-being. However, this relationship appears to be influenced by the person-activity fit, namely the extent to which an activity's features match certain characteristics of the person engaging in the activity. Evidence has proven the proposition that a high-level person-activity fit appears to be a major factor for engagement motivation and subsequently for PPIs' effectiveness (Schueller 2011, 2014). A proper person-activity fit can be supported by several features of a PPI, including the implementation of a variety of activities and the possibility of simultaneously engaging in several activities.

\subsection{PPIs for Teachers}

The effectiveness of PPIs embedded in private-life contexts has raised the question of whether workplace-related PPIs could be beneficial for workplace-related factors, such as job satisfaction, work engagement, and emotional exhaustion (McCullough 2015). In fact, a growing body of the literature provides evidence that PPIs tailored to a specific occupational context can be beneficial with regard to the aforementioned factors (e.g., Abbott et al. 2009; Demerouti et al. 2011; Donaldson et al. 2019; Liossis et al. 2009; Luthans et al. 2008, 2010; McCullough 2015; Millear et al. 2008; Ouweneel et al. 2013; Page and Vella-Brodrick 2013).

School teachers are likely to be a workforce in need of such programmes. Research clearly shows that the teaching profession systematically incorporates factors causing strain and stress, which can subsequently lead to a persistent negative mindset that causes psychological disorders and physical diseases, accounting for absenteeism and attrition (Aldrup et al. 2017; Andrew et al. 2018; Burke et al. 1996; Conley and Woosley 2000; Haydon et al. 2018; Kyriacou 2001; Montgomery and Rupp 2005; 
Wilson 2002). Hence, teacher stress, defined as 'the experiences by a teacher of unpleasant, negative emotions, such as anger, anxiety, tension, frustration, and/or depression, resulting from some aspect of work as a teacher' (Kyriacou 2001, p. 28), affects not only the health of individual teachers but also the people with whom they interact, such as students and colleagues. In fact, research findings hint at the connection between teachers' well-being and the performance of both teachers and students (e.g., Duckworth et al. 2009). In turn, positive emotions, thoughts, and behaviours can be regarded as resources that positively influence job satisfaction and work engagement, and negatively relate to the perception of demands (Bakker et al. 2007). It has been repeatedly argued that the job-related well-being of teachers has a profound impact on student well-being and the subsequently on the success of educational practices, teaching methods, and the teacher-student-relationship (e.g. McCallum, Price, Graham, and Morrison 2017). For that reason, Rahm and Heise (2019) concluded that investing in the well-being of teachers can not only be associated with individual health improvements, but also with positive effects on the quality of teaching and learning.

A few studies have begun to highlight the potential value of PPIs for teachers (Chan 2010, 2013; McCullough 2015; Rahm and Heise 2019). These studies have investigated the effects of standard strength-, savouring-, and gratitude-based interventions on teachers, which proved effective to some extent. However, the sample sizes were rather small $(N<100)$, and either longterm effects were not investigated (Chan 2010, 2013), or a control group was not included (McCullough 2015) or missing from the follow-up interval (Rahm and Heise 2019). Moreover, the studied activities neither focused on teachers and their occupational challenges nor contained a wider variety of activities to increase the person-activity fit. Hence, the effectiveness of the interventions were reported as being limited. For example, McCullough (2015) specified that some teachers in the sample had difficulties implementing character strengths in their daily work and consequently did not benefit from the positive activities.

\subsection{Intervention Design}

This study's approach envisaged an intervention and a placebo-controlled condition, which were parallelised in the technical procedure and the period of implementation. The participants under both intervention and placebo groups received one e-mail every 2 days over the course of 2 weeks (six e-mails in total), containing their respective condition-related instructions.

\subsubsection{Intervention Condition}

The intervention included a series of concise descriptions of six positive activities, based on already established PPIs, which were adapted to the occupational context of teachers. Basically, the short exercises were designed to elicit active engagement in either positive thinking or positive behaviours in the work environment. To provide variety, and hence individual choices, the activities were deliberately selected from six categories of positive psychology (see section 7). 


\subsubsection{Placebo Condition}

The participants under the placebo condition received digital cards with simple positivity sayings and the instruction to read and ponder on these contents. The sayings' themes were synchronised with the categories and their order in the intervention condition (see section 8).

\section{Research Question and Hypothesis}

Workplace-related PPIs were shown to be beneficial in enhancing job satisfaction and engagement and reducing emotional exhaustion (e.g., Donaldson et al. 2019; Liossis et al. 2009). However, the effects of the PPIs that are especially designed for school teachers are largely unknown. Some previous studies indicated the advantageous effects of PPIs in promoting well-being and minimising teacher stress (Chan 2010, 2013; McCullough 2015; Rahm and Heise 2019). However, the findings and their generalisability are limited due to the described shortcomings of the study and intervention designs. The present study focusses on the variables of job satisfaction, teacher engagement, and emotional exhaustion. These were selected as they can be regarded as relevant components of the job-related well-being of teachers. In accordance with the concept of subjective well-being (Diener 1984), job satisfaction represents the cognitive component, while teacher engagement and (the absence) of emotional exhaustion can be regarded as affective components of well-being. All three aspects appear to have sizable impacts on teachers' health and work performance. For example, it was reported, that job satisfaction is related to work performance (e.g., Caprara et al. 2006; Judge et al. 2001) and low job satisfaction can be regarded as a driver of stress and intentions to leave the profession (e.g., Ingersoll 2001). High work engagement positively influences work performance, organisational commitment, and the willingness to stay in an organisation (e.g., Hakanen et al. 2006). Engaged teachers were found to strive for the best ideas and teaching practises with the aim of providing the best possible conditions for student learning and for achieving positive effects on the engagement levels of students (Cardwell 2011). Emotional exhaustion not only endangers teachers' health but was also found to have severe negative effects on the motivation and achievement of students (e.g., Klusmann et al. 2016; Shen et al. 2015).

The present study addresses the following research question: To what extent does the proposed e-mail-based PPI for teachers exert effects on job satisfaction, teacher engagement, and emotional exhaustion?

Based on the reviewed research on PPIs, small to moderate effects are expected with regard to the following hypothesis:

H1. The participants assigned to the intervention group show a significantly stronger increase in job satisfaction compared with those assigned to the placebo group.

H2. The participants assigned to the intervention group show a significantly stronger increase in teacher engagement compared with those assigned to the placebo group. 
H3. The participants assigned to the intervention group show a significantly stronger decrease in emotional exhaustion compared with those assigned to the placebo group.

\section{Research Method}

To investigate the research question, a randomised placebo-controlled field experiment ( 2 groups $\times 3$ times) was conducted. German in-service teachers were surveyed in a longitudinal study at three intervals (see Fig. 1). The participants were recruited by email promotion and had to voluntarily register in the programme. The study was conducted during the second half of the school year in March 2019.

\subsection{Participants}

In total, 309 German school teachers aged 26-65 years $(M=49.28$; SD $=9.97)$ participated in the study. The sample consisted of 200 women (64.7\%) and 105 men (33.9\%); four data entries for gender were missing. On average, the teachers in the sample had $M=23.53$ years $(\mathrm{SD}=12.6)$ of teaching experience. The participants represented

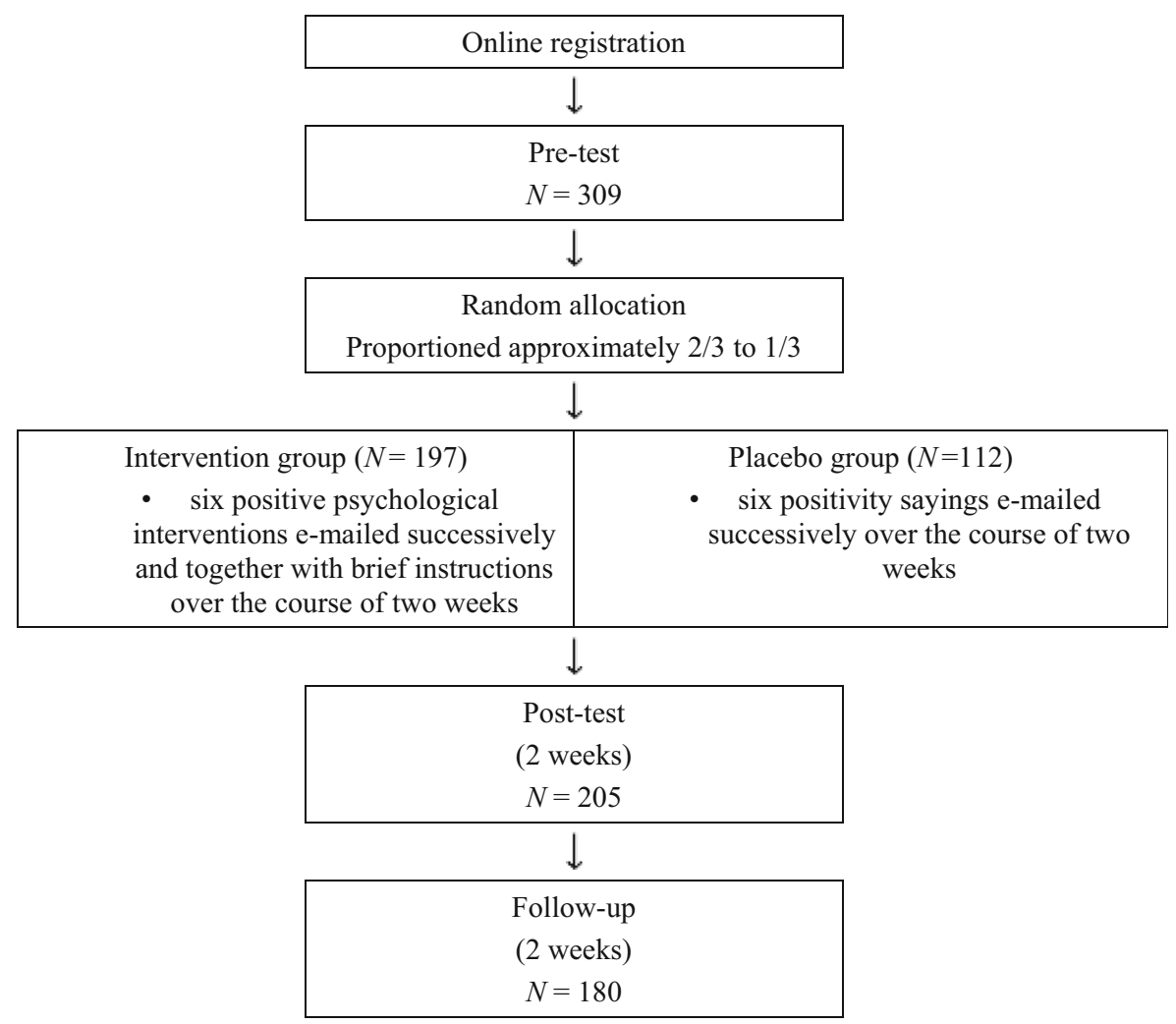

Fig. 1 Flowchart of procedure 
primary $(23.9 \%)$, secondary $(14.2 \%)$, grammar $(20.4 \%)$, vocational $(22.1 \%)$, and other school types $(17.1 \%)$.

Of the total sample, 197 were randomly assigned to the intervention group and 112 to the placebo group. An approximately 2-to-1 ratio was chosen to provide more participants with the proper intervention. The groups did not differ regarding their mean age $(\mathrm{F}(1,291)=.09, p=.76)$, years of experience $(\mathrm{F}(1,301)=.93, p=.34)$, and gender ratio $\left(\chi^{2}(N=305)=2.27, p=.31\right)$.

Of the 197 participants assigned to the intervention group, 115 completed the posttest $(58.4 \%)$, and 101 completed the follow-up questionnaire $(51.2 \%)$. The teachers who participated at all three intervals comprised mainly women (67\%), aged 26-64 $(M=49.15 ; \mathrm{SD}=10.39)$ and with an average of $M=22.62$ years $(\mathrm{SD}=12.3)$ of teaching experience. The participants represented primary $(23.2 \%)$, secondary $(14.3 \%)$, grammar $(21.4 \%)$, vocational $(24.1 \%)$, and other school types (17\%).

Of the 112 participants assigned to the placebo group, 97 completed the post-test $(86.6 \%)$, and 88 completed the follow-up questionnaire $(78.5 \%)$. The teachers who participated at all three intervals comprised mainly women $(60.7 \%)$, aged 26-65 $(M=$ 49.52; $\mathrm{SD}=9.19)$ and with an average of $M=24.08$ years $(\mathrm{SD}=12.7)$ of teaching experience. The participants represented primary (24.4\%), secondary (14.2\%), grammar $(19.8 \%)$, vocational $(24.4 \%)$ and other school types $(17.3 \%)$.

Of the initial 309 pre-test participants, 212 completed pre- and post-tests, and 180 completed all three intervalls, with the following percentages of attendance: $100 \%$ at time $1,68.6 \%$ at time 2 , and $63.6 \%$ at time 3 . The dropout rates appeared to be within the usual range indicated in PPI studies (e.g., Gander et al. 2013). Additionally, despite the dropouts, the gathered data still largely exceeded the sample sizes of comparable prior studies on PPIs for teachers (e.g., Chan 2010, 2013; McCullough 2015). The participants with and without missing data were compared over all involved dependent variables. For both the entire sample and for the two separate groups no statistically significant differences between remaining participants and drop-outs were detected. The missing data were handled using the full-information maximum likelihood estimation. This allowed the use of all available data, reducing the bias in parameter estimation that would result from missing data, as well as increasing statistical power (Enders 2010).

\subsection{Instruments}

Table 1 provides an overview of the applied measures. Job satisfaction was assessed using a German translation of a six-item teaching satisfaction scale (Ho and Au 2006). Teacher engagement was measured by applying a German version of the engaged teacher scale (Klassen et al. 2013), constituting four subscales (cognitive engagement, emotional engagement, social engagement: students, and social engagement: colleagues) and hence covering a wide range of engagement facets. It has been shown to be valid and reliable internationally (Yelderen et al. 2018). Emotional exhaustion was assessed by a German version of the emotional exhaustion subscale from the Maslach Burnout Inventory (Maslach et al. 1996) - the prevalent measure in this regard. The items were rated on a 5-point scale (from $1=$ 'does not apply' to $5=$ 'fully applies'). All measures and additional questionnaires (e.g., interval 1: sociodemographic data, interval 2: recommended use of intervention and process quality) were incorporated into three online questionnaires, one for each interval. 


\subsection{Data Analysis}

The preliminary analyses included the dropouts and the handling of missing data (see subsection 4.1). The measurement scales were tested for internal consistency. The results are reported in Table 1. The descriptive data was checked for plausibility. As the hypotheses were tested mostly using analyses of variance (MANOVA, ANOVAs) and t-tests, the preliminary analyses also tested for the approximate normal distribution and sphericity.

\section{Results}

\subsection{Descriptive Findings}

Table 2 shows the breakdown of the means and the standard deviations for all factors, intervals, and groups. While the means for job satisfaction and emotional exhaustion had medium rates at interval 1 , the means for teacher engagement were above the theoretical scale average of 2.5. In the intervention group, the means indicated increased job satisfaction, a positive change in teacher engagement, and decreased emotional exhaustion from interval 1 to 2 . From interval 2 to 3, another smaller mean change was identified under the intervention condition.

To investigate the relationships of the studied factors, Pearson correlations for all factors at all intervals were computed. As exemplified for the pre-test interval (Table 3), the applied measures appeared to be plausibly interrelated in terms of the effect size and the direction of the relationships. The teachers who were more satisfied with their jobs also reported higher engagement and lower emotional exhaustion. The more engaged teachers reported lower emotional exhaustion as well. The correlations were statistically significant and of small to medium degrees.

\subsection{Main Results}

In testing the hypotheses, ANOVAs with repeated measures were computed by analysing the effects of time, as well as the effects of time $\times$ group interactions. In the case of indicated effects, subsequent contrast analyses were performed to specify

Table 1 Overview of applied measures

\begin{tabular}{|c|c|c|c|}
\hline Factor & Measure & $\begin{array}{l}\text { Item example } \\
\text { (total number of items) }\end{array}$ & $\begin{array}{l}\text { Cronbach's } \\
\alpha \text { range }\end{array}$ \\
\hline Job satisfaction & $\begin{array}{l}\text { Teaching satisfaction scale } \\
\quad \text { (Ho and } \mathrm{Au} 2006)\end{array}$ & $\begin{array}{l}\text { 'I am satisfied with } \\
\text { being a teacher.' (6) }\end{array}$ & $.79-.87$ \\
\hline Teacher engagement & $\begin{array}{l}\text { Engaged teacher scale } \\
\text { (Klassen et al. 2013) }\end{array}$ & 'I love teaching.' (12) & $.79-.81$ \\
\hline Emotional exhaustion & $\begin{array}{l}\text { Emotional exhaustion subscale } \\
\text { from the Maslach Burnout } \\
\text { Inventory (Maslach et al. 1996) }\end{array}$ & $\begin{array}{l}\text { 'I feel emotionally drained } \\
\text { by my work.' (9) }\end{array}$ & $.81-.91$ \\
\hline
\end{tabular}


Table 2 Descriptive data for all measures at all three intervals

\begin{tabular}{|c|c|c|c|c|c|c|c|c|c|}
\hline \multirow[b]{2}{*}{ Variable } & \multicolumn{3}{|c|}{ Pre-intervention } & \multicolumn{3}{|c|}{ Post-intervention } & \multicolumn{3}{|c|}{ Follow-up } \\
\hline & $N$ & $M$ & $S D$ & $N$ & $M$ & $S D$ & $N$ & $M$ & $S D$ \\
\hline \multicolumn{10}{|c|}{ Job satisfaction } \\
\hline IG & 197 & 3.48 & 0.78 & 101 & 3.73 & 0.70 & 101 & 3.72 & 0.69 \\
\hline PG & 112 & 3.39 & 0.63 & 95 & 3.30 & 0.81 & 83 & 3.36 & 0.83 \\
\hline \multicolumn{10}{|c|}{ Teacher engagement } \\
\hline IG & 197 & 4.06 & 0.40 & 115 & 4.25 & 0.45 & 101 & 4.20 & 0.50 \\
\hline PG & 112 & 3.99 & 0.16 & 97 & 4.05 & 0.18 & 79 & 4.04 & 0.17 \\
\hline \multicolumn{10}{|c|}{ Emotional exhaustion } \\
\hline IG & 197 & 2.88 & 1.05 & 115 & 2.57 & 0.80 & 101 & 2.47 & 0.93 \\
\hline PG & 108 & 2.82 & 1.05 & 90 & 2.89 & 0.81 & 81 & 2.84 & 0.92 \\
\hline
\end{tabular}

$I G$ intervention group, $P G$ placebo group

each effect's type and magnitude. On request of a reviewer a MANOVA, including all three outcome variables, was carried out as an additional sensitivity test. It pointed to statistically significant effects of time $(F(6,630)=3.39 ; p<.003)$ and group $\times$ time interaction $(F(6,630)=7.99 ; p<.000)$.

\subsubsection{Job Satisfaction}

Regarding hypothesis 1 , a repeated-measure ANOVA indicated a statistically significant effect of the group $\times$ time interaction $(F(2,169)=7.98 ; p<.000)$ on job satisfaction. As the post-hoc testing revealed, the groups did not differ significantly at interval $1(t(307)=11.28 ; p=.80)$, but differed significantly at interval $2(t(194)=$ $8.12 ; p=.002 ; d=.58)$ and interval $3(t(182)=4.83 ; p<.000 ; d=.49)$. For the intervention group, the average job satisfaction increased in comparison to pre- and post-intervention measurements $(F(1,100)=21.62 ; p<.000)$. The size of this increase $(d=.34)$ would be characterised as a small effect (Cohen 1992). However, there was no significant change in job satisfaction from interval 2 to $3(F(1,88)=4.68 ; p=.33)$. The placebo group showed no significant change in job satisfaction when contrasting intervals 1 and $2(F(1,94)=.47 ; p=.49)$ and intervals 2 and $3(F(1,81)=3.09$; $p=.82$ ). According to hypothesis 1 , the intervention group would show a significantly

Table 3 Pearson correlations amongst factors

\begin{tabular}{|c|c|c|c|c|c|c|c|c|c|}
\hline \multirow[t]{2}{*}{ Variable } & \multicolumn{3}{|c|}{ Pre-intervention } & \multicolumn{3}{|c|}{ Post-intervention } & \multicolumn{3}{|c|}{ Follow-up } \\
\hline & 1 & 2 & 3 & 1 & 2 & 3 & 1 & 2 & 3 \\
\hline 1 Job satisfaction & 1 & $.43 * *$ & $-.82 * *$ & 1 & $.40^{* *}$ & $-.77 * *$ & 1 & $.38 * *$ & $-.77 * *$ \\
\hline 2 Teacher engagement & $.43 * *$ & 1 & $-.48 * *$ & $.40 * *$ & 1 & $-.43 * *$ & $.38 * *$ & 1 & $-.39 * *$ \\
\hline 3 Emotional exhaustion & $-.82 * *$ & $-.48 * *$ & 1 & $-.77 * *$ & $-.43 * *$ & 1 & $-.77 * *$ & $-.39 * *$ & 1 \\
\hline
\end{tabular}

$* * p<0.01$ 
stronger increase in job satisfaction compared with the placebo group (see Fig. 2). Moreover, the increased job satisfaction of the intervention group showed no change 2 weeks after the intervention.

\subsubsection{Teacher Engagement}

Regarding hypothesis 2 , a repeated-measure ANOVA revealed a statistically significant effect of the group $\times$ time interaction $(F(1,178)=173.46 ; p<.000)$ on teacher engagement. Post-hoc testing showed that the groups did not differ significantly at interval $1(t(307)=3.09 ; p=.24)$, but differed significantly at interval $2(t(201)=3.98$; $p<.000 ; d=.53)$ and interval $3(t(178)=2.73 ; p=.003 ; d=.39)$. For the intervention group, the average teacher engagement increased in comparison to pre- and postintervention measurements $(F(1,114)=15.52 ; p<.000)$. The size of this increase $(d=.45)$ would be characterised as a small effect (Cohen 1992). However, there was no significant change in mean job satisfaction from interval 2 to $3(F(1,100)=3.09$; $p=.82)$. The placebo group showed no significant change in job satisfaction when contrasting intervals 1 and $2(F(1,87)=4.39 ; p=.39)$ and intervals 2 and $3(F(1$, $81)=.32 ; p=.57)$. In conclusion, the intervention group showed a significantly stronger increase in teacher engagement compared with the placebo group (Fig. 3) providing support for hypothesis 2 . Moreover, the increased teacher engagement of the intervention group did not significantly change 2 weeks after the intervention.

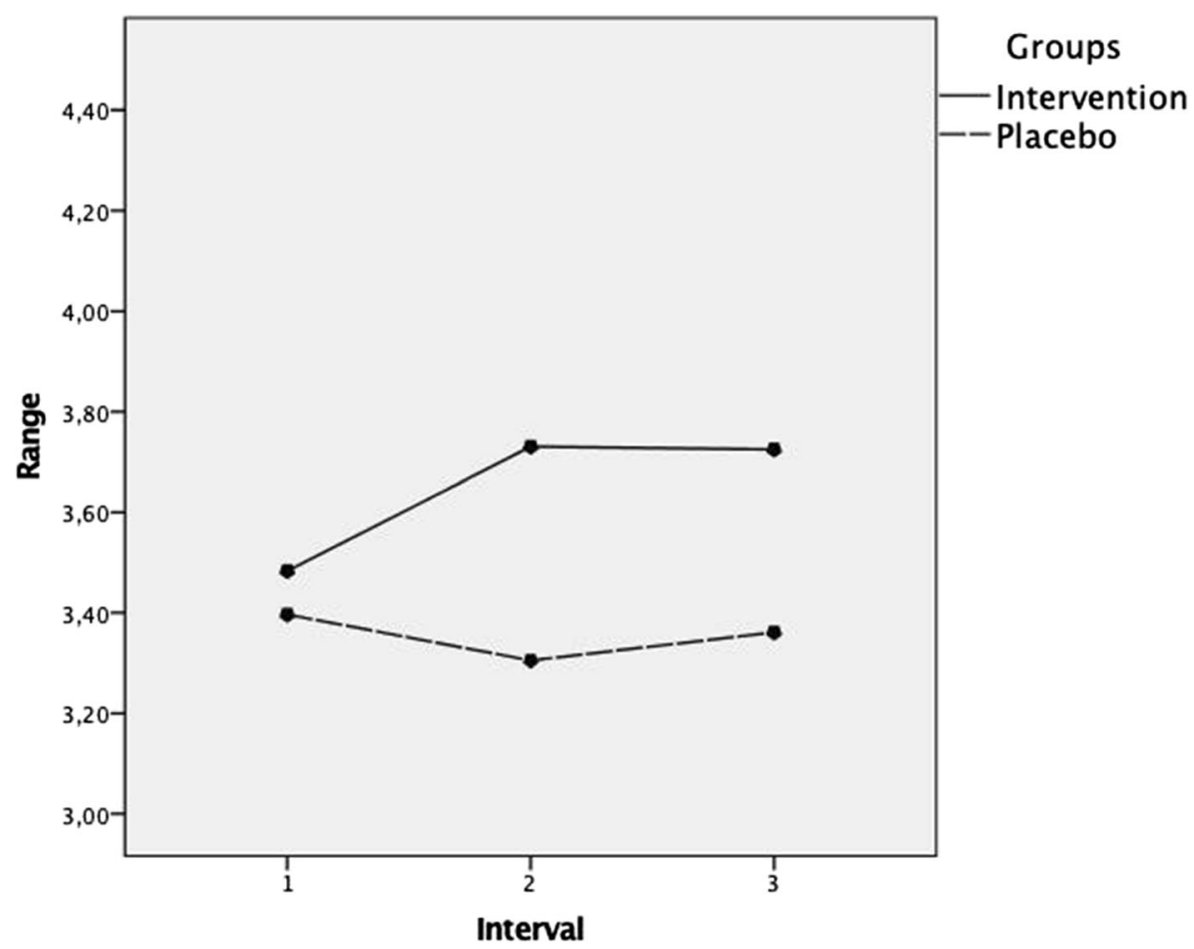

Fig. 2 Comparative change in job satisfaction of intervention and placebo groups, as indicated by pre-test, post-test and follow-up measurement 


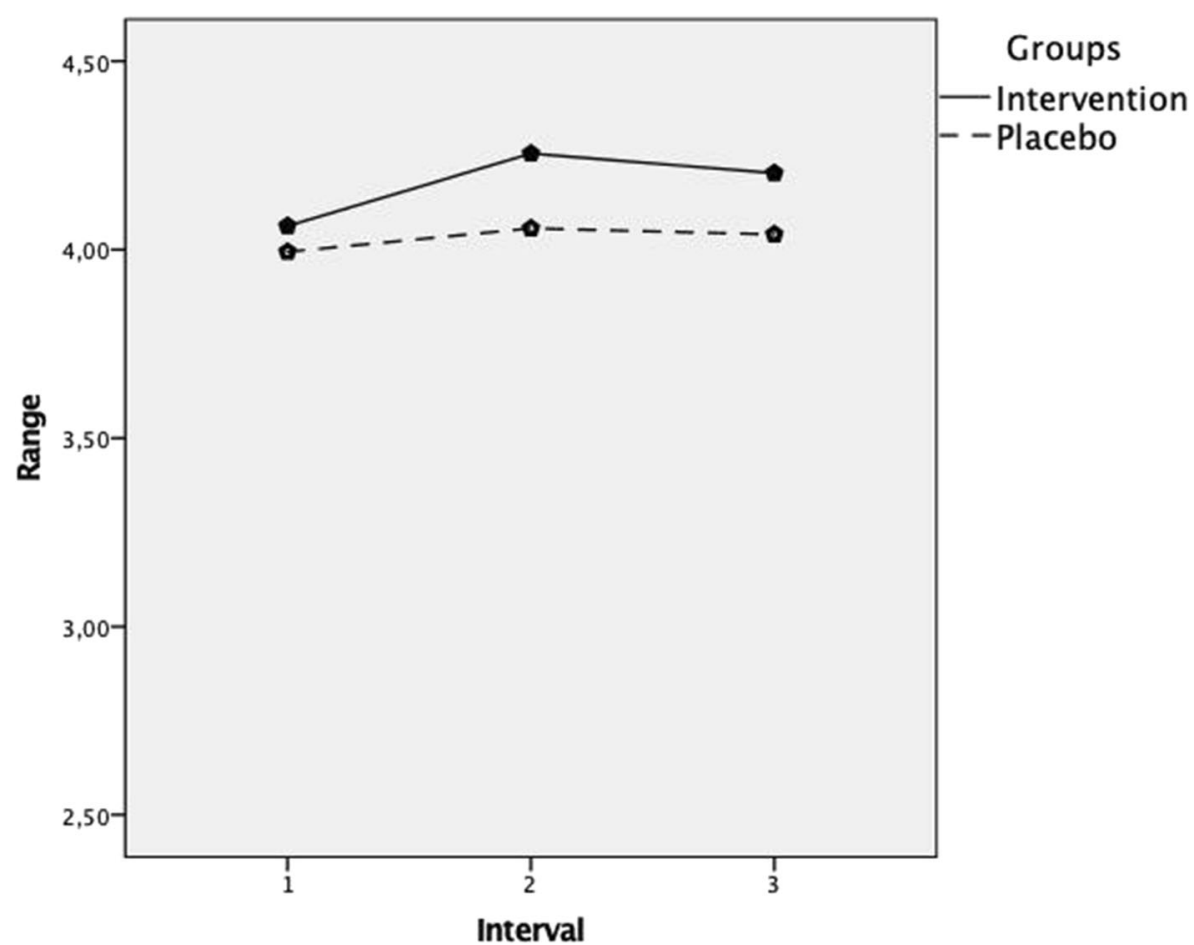

Fig. 3 Comparative change in teacher engagement of intervention and placebo groups, as indicated by pretest, post-test and follow-up measurement

\subsubsection{Emotional Exhaustion}

Regarding hypothesis 3, a repeated-measure ANOVA revealed a statistically significant effect of the group $\times$ time interaction $(F(2,344)=9.84 ; p<.000)$ on emotional exhaustion. As post-hoc contrasts revealed, the groups did not differ significantly at interval $1(t(287)=1.62 ; p=.10)$, but differed significantly at interval $2(t(203)=-1.68 ; p=.004, d=.40)$ and interval $3(t(180)=$ $-1.77 ; p=.003 ; d=.40)$. The intervention group's average emotional exhaustion significantly decreased when comparing pre- and post-intervention measurements $(F(1,110)=14.04 ; p<.000)$. The size of this decrease $(d=.32)$ would be characterised as a small effect (Cohen 1992). The intervention group showed a further decrease in emotional exhaustion from interval 2 to $3(F(1,100)=$ $36.89 ; p<.000)$. The size of this decrease $(d=0.12)$ would also be characterised as a small effect (Cohen 1992). The placebo group had no significant change in emotional exhaustion when contrasting intervals 1 and 2 $(F(1,85)=.39 ; p=.53)$ and intervals 2 and $3(F(1,80)=1.46 ; p=.20)$. According to hypothesis 3 , the intervention group would show a significantly stronger decrease in emotional exhaustion compared with the placebo group (Fig. 4). Moreover, the decreasing trend slightly continued 2 weeks after the intervention. 


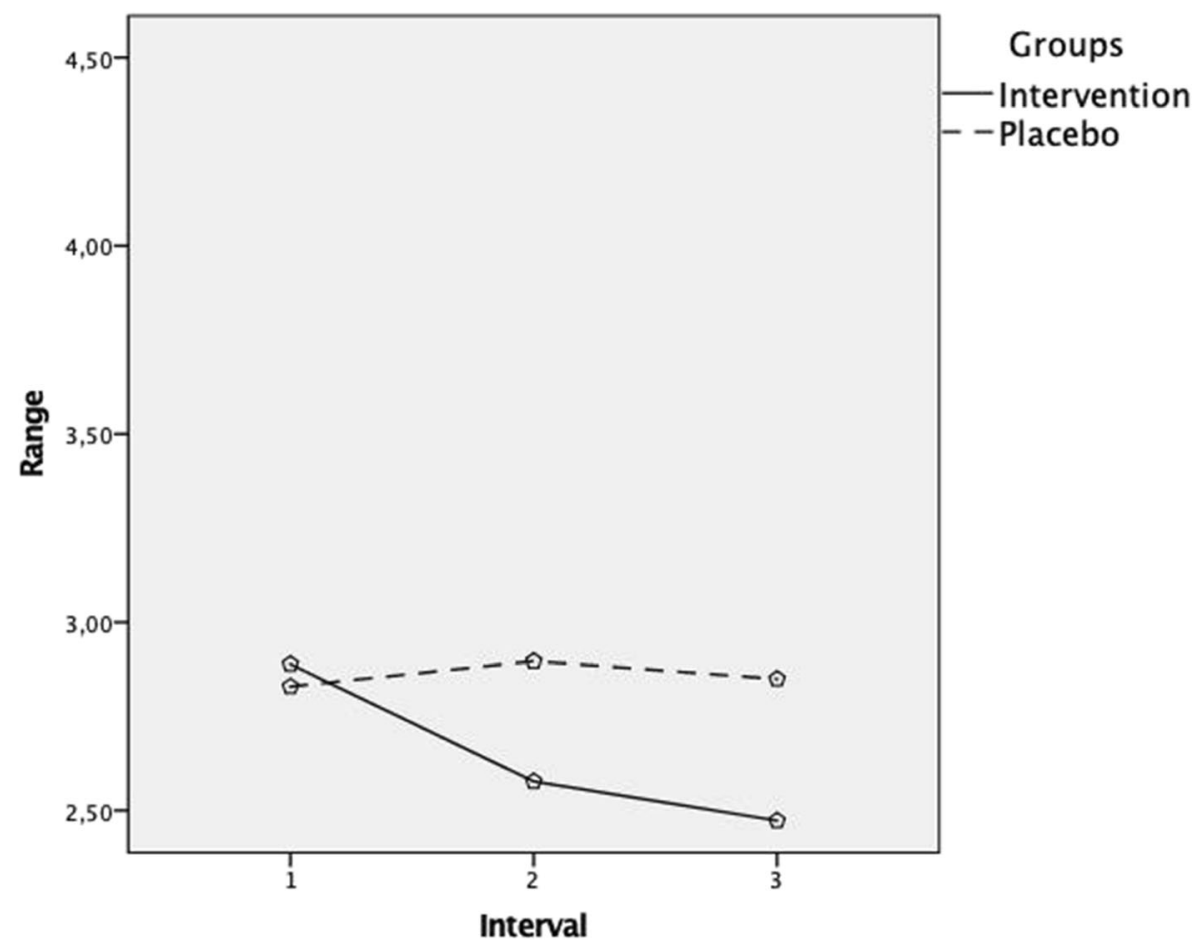

Fig. 4 Comparative change in emotional exhaustion of intervention and placebo groups, as indicated by pretest, post-test and follow-up measurement

\subsubsection{Additional Analyses}

Additionally, the intervention's perceived quality and usability were analysed. The majority of the intervention group participants surveyed at interval $2(n=197)$ agreed that the activity descriptions were designed emotively $(80.3 \%)$ and that the activities stimulated a more positive perception of everyday school life $(77.4 \%)$. More than half of the teachers also reported that the activities stimulated them to more actively engage in positive behaviour at work $(56.5 \%)$. The majority of the participants considered the programme viable in the work context $(79.3 \%)$ and adaptable to their daily work routines $(60.9 \%)$. Most participants $(98.2 \%)$ valued the programme's e-mail-based approach. All intervention group participants reported having actively engaged in at least four of the six activities. At interval 3, over half of the teachers $(60.9 \%)$ noted that they were still engaging in some activities, while some also planned on continuing to use the activities in their workplace $(56.5 \%)$.

\section{Discussion}

Although fostering teachers' well-being and positivity is described as desirable and promising with respect to being beneficial for their mental health and productivity, functional and effective tools are lacking (McCullough 2015). Interventions from the 
field of positive psychology offer potentials in this regard; however, the PPIs' application to the teachers' work context has rarely been implemented and studied. The few existing studies were based on rather small sample sizes $(<100)$ and either did not investigate the conducted programmes' long-term effects or did not involve a control group (Chan 2010, 2013; McCullough 2015). Moreover, the investigated PPIs employed limited variability and hence restricted possibilities for the person-activity fit, which could have impeded their potential effectiveness.

This paper has presented a field experiment, involving one intervention group and one placebo group, assessing the effect of PPI on job satisfaction, teacher engagement, and emotional exhaustion at three intervals. Based on the positive-activity model (Lyubomirsky and Layous 2013) and on prior findings, the compiled e-mail-based intervention was expected to contribute to a small- to medium-sized increase in job satisfaction and teacher engagement, as well as to a decrease in the teachers' emotional exhaustion.

The results showed the investigated intervention programme's association with increased job satisfaction and teacher engagement, as well as decreased emotional exhaustion. The small effect sizes are in line with most of the prior findings regarding online-based PPI (e.g., Bolier and Abello 2014). Moreover, gains in job satisfaction and teacher engagement were still presented 2 weeks after the intervention. This should be highlighted because prior studies on PPIs for teachers commonly did not examine longterm effects. Nevertheless, the persistence of an effect is in line with the findings from the PPIs studied in other work environments and in private-life contexts (e.g., Bolier et al. 2013). As an exception, the mean emotional exhaustion not only decreased during the time of the intervention but also in the 2 weeks following the programme. As this decrease was only present in the intervention group but not in the placebo group, it seemed associated with the programme. One probable cause of the extended reduction in emotional exhaustion could be the teachers' continued engagement in some of the activities after the end of the programme. According to the positive-activity model (Lyubomirsky and Layous 2013), the continued use of PPIs is supported by certain features of the person, such as motivation and effort. In fact, a Pearson correlation revealed a small but significant negative relationship $(r=-.21 ; p=.03)$ between the participants' intention to continuously engage in positive activities at interval 2 and their emotional exhaustion at interval 3. Although this result might provide some empirical support for the offered explanation, post-intervention effects and their causes need to be addressed much more thoroughly in future studies. Here also the question needs to be answered, why the prolonged effect was present only with emotional exhaustion, but not with job satisfaction or teacher engagement. It could be possible, that participants decided to further engage only in certain activities, which may be (unbeknownst to them) more suitable to reduce emotional exhaustion. This highlights the need to disentangle the effects of the implemented activities. This could be achieved by the implementation of several measures. For example, by using methods of experience sampling, by implementing multiple intervention conditions with single activities only, or by systematic alterations of certain activity-sets (e.g., self- vs. otheroriented or active vs. passive activities). However, it is likely that the prolonged effect is not simply the result of single activities, but results from a shift in perspective that occurs through participation in the programme. As Walton (2014) explains, proper interventions do not change "a moment in time", but spark a process that unfolds subsequently (p. 76). This perspective suggests that participants - inspired by, but not 
dependent on the activities - might set out to change certain aspects of their job life which result in a prolonged decrease in emotional exhaustion.

In summary, the findings presented here add weight to the proposed potential of positive interventions for teachers. They also indicate that an effective online-based PPI, with its scalability, ease of use, and high acceptance rates, could be developed into a widely used tool for fostering school teachers' job-related well-being. However, prior to this, more research is needed to both replicate and further substantiate the reported findings and to provide a better understanding of the relevant psychological mechanisms behind positive activities (Lyubomirsky and Layous 2013). This includes the proper measurement and investigation of the person-activity fit and its effects (Schueller 2014).

Future research should also tackle the following limitations of the present study. First, while the initial sample size was larger than those of comparable prior studies (Chan 2010, 2013; McCullough 2015), the dropout rates were fairly high and might limit the findings' generalisability. Although the dropouts did not differ in their initial results from the participants who stayed in the sample, the attrition posed problems regarding statistical power and certain estimation biases. In the studied case, the click rates showed that the majority of the teachers continuously participated in the programme (opened e-mails and downloaded activity descriptions). Despite these response rates, only approximately $60 \%$ of the participants provided their data in the follow-up questionnaires. One reason for this could be observed in the e-mail-based approach of the study. While obviously most of the teachers happily participated in the programme, they did not feel committed enough to also provide their data, possibly because there was no one to identify and interact with in person. Second, compared with other studies, the follow-up measure's two-week time span seemed rather short. While follow-up time spans amounted to a month or longer in other PPI studies (Bolier et al. 2013), it should be recognised that in these cases, the duration of the intervention were often much longer as well (e.g., 1 month and more). In this regard, the present study's procedure is consistent with the usual implementation of a 1:1 relation concerning the intervention duration and the follow-up measurement's time span. Third, the entire study was based on self-reports. While this approach appears to be absolutely typical for studying the effects of PPIs, it poses several known problems. Self-reports are prone to method bias and can inflate the correlations between measures (Blume et al. 2010). However, the potential effects of this bias were minimised by using anonymised questionnaires, and by providing sufficient time and support for filling them out. Most importantly, the longitudinal design reduced the contamination of the success measures because they were recorded separately and with a temporal distance from each other. Nevertheless, future research could incorporate observations or biopsychological data to corroborate the effects of PPIs.

Despite these limitations the presented study shows that educational research can contribute to tackling "educator stress" at the individual level. Stress in the education sector appears to be a global job-related problem. However, it must also be stated that stress and strain resulting from system-related working conditions can and must not be resolved on the individual level, but requires systemic improvements through interventions at the level of school administrators and policy makers. Given its advances in research methodology and intervention methods McIntyre et al. (2017) argue in favour of a stronger involvement of educational research in order to provide data for all levels of decision making and effective interventions for practitioners in 
schools. In this regard, positive psychology poses an invaluable resource as it provides relevant resources and methods for improving educational systems and practises (see also Seligman and Adler 2019; Waters and Loton 2019).

Funding Information Open Access funding provided by Projekt DEAL.

\section{Compliance with Ethical Standards}

Conflict of Interest The author declares to have no conflict of interest.

Ethical Approval This article does not contain any studies with human participants or animals performed by any of the authors.

\section{Sample material for intervention condition}
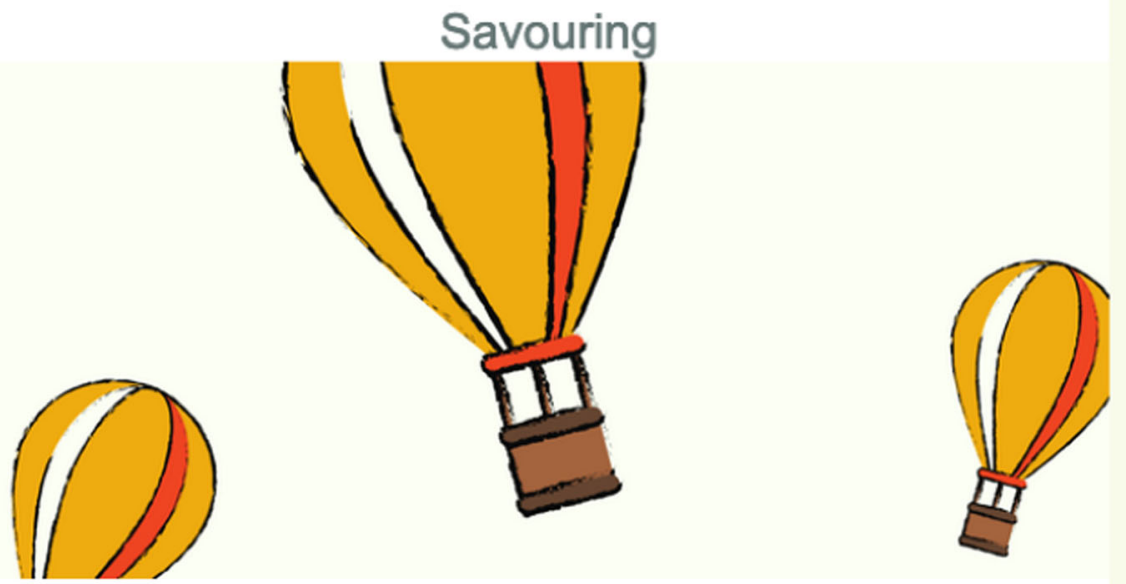

Today's activity is about savouring. All to rarely do we take some time to really enjoy our achievements.

Today, we are going to change just that!

Please download and read the instructions provided with this e-mail. Try to actively engage in this activity during the next two school days.

\section{With positive regards,}

Name

Fig. 5 Sample e-mail (translated from German) 
Table 4 Description of the 6 positive activities

\begin{tabular}{lll}
\hline Nr. Concept Activity & Instruction & Based on
\end{tabular}

1 savouring benefits of the job Participants were instructed to mentally visualize and savour the benefits

Bryant et al. 2005; of their job.

2 gratitude gratitude walk

Participants were instructed to roam the school grounds or take a walk on their way from work, picturing things Keeney 2009 they are grateful for with regard to their present working day.

3 optimism positivity boosters Participants were instructed to write down a list with words representing personal triggers of positive emotions. The list could contain previous work-related experiences of success, planned daily spare time activities as well as highlights of the upcoming school year. Participants were instructed to glance at the list, whenever they needed a positive boost during the school day.

4 strengths teacher strengths

Participants were instructed to enlist personal strengths that support them in flourishing as a teacher. Furthermore, they were instructed to pick one strength and deliberately use it during the next school days. They also were hinted to closely focus on the positive outcomes of their strength-related behaviour.

5 meaning meaning emblem Participants were instructed to identify or

Dik et al. 2009 design an emblem representing the personal reasons for engaging in teaching. Furthermore, participants were instructed to put their meaning emblem in places they encounter on a daily basis (e.g. calendar, desktop wallpaper).

$6 \quad$ kindness

Participants were instructed to write a friendly e-mail to the parents of the pupils from their class, providing a positive recapitulation of the week's events and achievements.

King 2001;

Lyubomirsky et al. 2011

McCullough 2015

\author{
Chan 2013; Emmons \\ and McCullough \\ 2003
}




\section{Sample material for placebo condition}
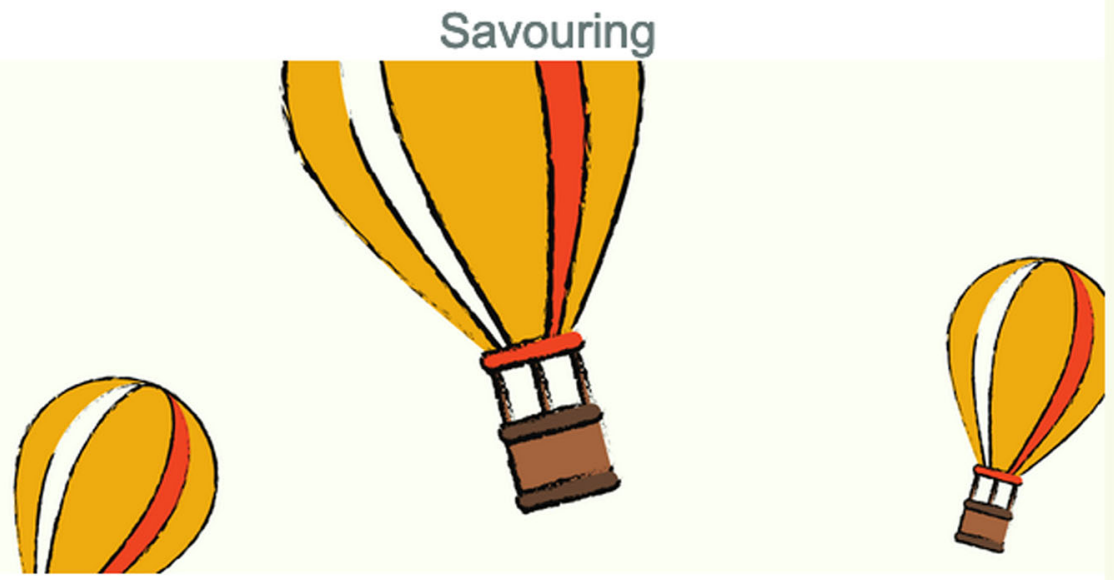

Today's activity is about savouring. All to rarely do we take some time to really enjoy our achievements.

Today, we are going to change just that!

Please download and read the inspiring card provided with this e-mail. Try to act in accordance with this mindset during the next two school days.

With positive regards,

Name

Fig. 6 Sample e-mail (translated from German) 


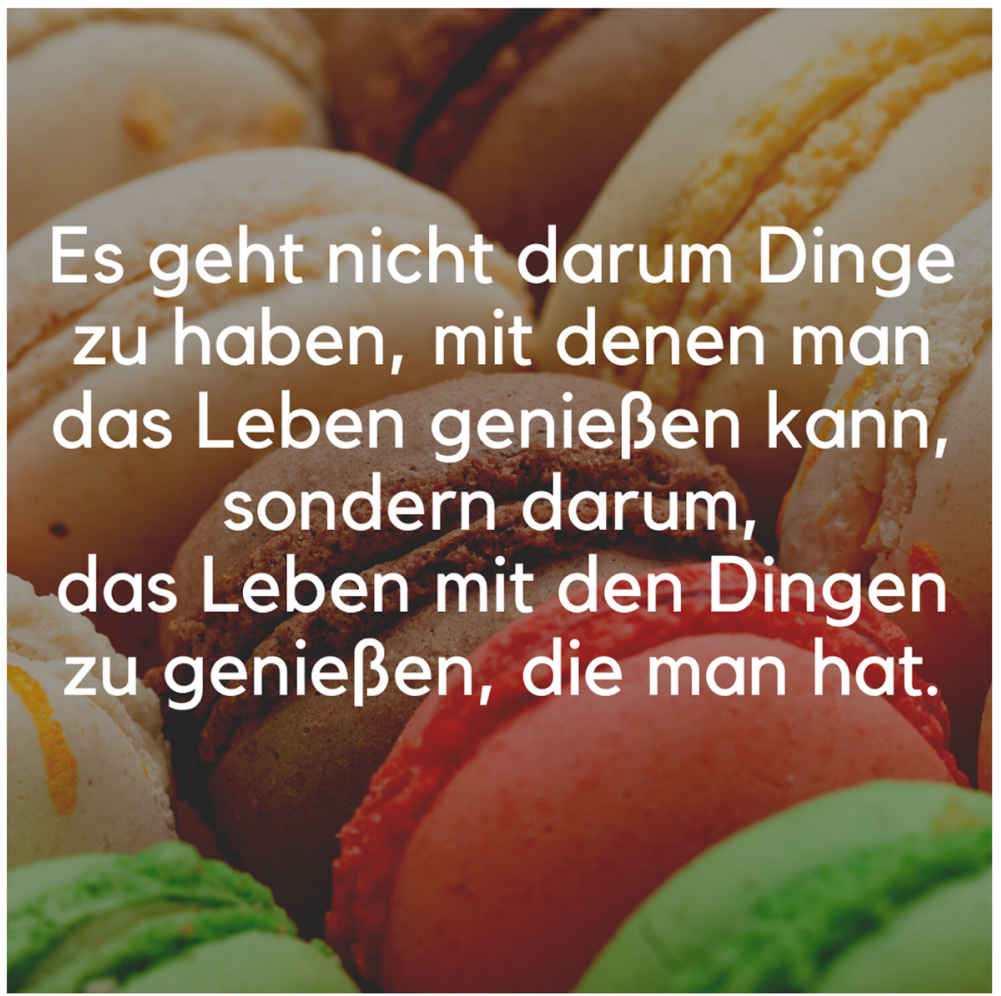

Fig. 7 Sample card with positivity saying (gratitude)

Loose Translation: 'Life is not about owning things that provide enjoyment, but about enjoying the things you own.'

Open Access This article is licensed under a Creative Commons Attribution 4.0 International License, which permits use, sharing, adaptation, distribution and reproduction in any medium or format, as long as you give appropriate credit to the original author(s) and the source, provide a link to the Creative Commons licence, and indicate if changes were made. The images or other third party material in this article are included in the article's Creative Commons licence, unless indicated otherwise in a credit line to the material. If material is not included in the article's Creative Commons licence and your intended use is not permitted by statutory regulation or exceeds the permitted use, you will need to obtain permission directly from the copyright holder. To view a copy of this licence, visit http://creativecommons.org/licenses/by/4.0/.

\section{References}

Abbott, J., Klein, B., Hamilton, C., \& Rosenthal, A. (2009). The impact of online resilience training for sales managers on wellbeing and performance. E-Journal of Applied Psychology, 5(1), 89-95.

Aldrup, K., Klusmann, U., \& Lüdtke, O. (2017). Does basic need satisfaction mediate the link between stress exposure and well-being? A diary study among beginning teachers. Learn Instr, 50, 21-30.

Andrew, K., Richards, R., Hemphill, M. A., \& Templin, T. J. (2018). Personal and contextual factors related to teachers' experience with stress and burnout. Teachers and Teaching, 24(7), 768-787. 
Bakker, A. B., Hakanen, J. J., Demerouti, E., \& Xanthopoulou, D. (2007). Job resources boost work engagement, particularly when job demands are high. J Educ Psychol, 99(36), 171-185.

Blume, B. D., Ford, J. K., Baldwin, T. T., \& Huang, J. L. (2010). Transfer of training: a meta-analytic review. J Manag, 36(4), 1065-1105.

Bolier, L., \& Abello, A. M. (2014). Online positive psychological interventions: State of the art and future directions. In A. C. Parks \& S. M. Schueller (Eds.), The Wiley-Blackwell handbook of positive psychological interventions (pp. 286-309). Chichester: Wiley Blackwell.

Bolier, L., Haverman, M., Westerhof, G. J., Riper, H., Smit, F., \& Bohlmeijer, E. (2013). Positive psychology interventions: a meta-analysis of randomized controlled studies. BMC Public Health, 13(119).

Bryant, F. B., Smart, C. M., \& King, S. P. (2005). Using the past to enhance the present: boosting happiness through positive reminiscence. Journal of Happiness Studies, 6, 227-260.

Buonomo, I., Fatigante, M., \& Fiorilli, C. (2017). Teachers' burnout profile: risk and protective factors. The Open Psychology Journal, 10(1), 190-201.

Burke, R. J., Greenglass, E. R., \& Schwarzer, R. (1996). Predicting teacher burnout over time: effects of work on stress, social support, and self-doubts on burnout and its consequences. Anxiety Stress Coping, 9, 261-275.

Caprara, G. V., Barbaranelli, C., Steca, P., \& Malone, P. S. (2006). Teachers' self-efficacy beliefs as determinants of job satisfaction and students' academic achievement: a study at the school level. J Sch Psychol, 44, 473-490.

Cardwell, M. E. (2011). Patterns of relationships between teacher engagement and student engagement. Education Doctoral. Paper 49.

Chan, D. W. (2010). Gratitude, gratitude intervention and subjective well-being among Chinese school teachers in Hong Kong. Educ Psychol, 30(2), 139-153.

Chan, D. W. (2013). Counting blessings versus misfortunes: positive interventions and subjective well-being of Chinese school teachers in Hong Kong. Educ Psychol, 33(4), 504-519.

Cohen, J. (1992). A power primer. Psychol Bull, 112, 155-159.

Conley, S., \& Woosley, S. A. (2000). Teacher role stress, higher order needs and work outcomes. Journal of Educational Administration, 38(2), 179-201. https://doi.org/10.1108/09578230010320163.

Demerouti, E., Van Eeuwijk, E., Snelder, M., \& Wild, U. (2011). Assessing the effects of a 'personal effectiveness' intervention on psychological capital, assertiveness and self-awareness using self-other agreement. Career Dev Int, 16(1), 60-81.

Diener, E. (1984). Subjective well-being. Psychol Bull, 95(3), 542-557.

Dik, B. J., Duffy, R. D., \& Eldridge, B. M. (2009). Calling and vocation in career counselling: recommendations for promoting meaningful work. Professional Psychology: Research and Practice, 40, 625-632.

Donaldson, S. I., Lee, J. Y., \& Donaldson, S. I. (2019). Evaluating positive psychology interventions at work: a systematic review and meta-analysis. International Journal of Applied Positive Psychology, 4(3), 113-134.

Duckworth, A., Quinn, P. D., \& Seligman, M. E. (2009). Positive predictors of teacher effectiveness. J Posit Psychol, 4(6), 540-547.

Emmons, R. A., \& McCullough, M. E. (2003). Counting blessings versus burdens: an experimental investigation of gratitude and subjective well-being in daily life. Journal of Personality and Social Psychology, 84, 377-389.

Enders, C. K. (2010). Applied missing data analysis. New York: Guilford Press.

Gander, F., Proyer, R. T., Ruch, W., \& Wyss, T. (2013). Strength-based positive interventions: further evidence for their potential in enhancing well-being and alleviating depression. J Happiness Stud, 14, 1241-1259.

Gibbs, S., \& Miller, A. (2014). Teachers' resilience and well-being: a role for educational psychology. Teach Teach Theory Pract, 20(5), 609-621.

Hakanen, J. J., Bakker, A. B., \& Schaufeli, W. B. (2006). Burnout and work engagement among teachers. $J$ Sch Psychol, 42(6), 495-513.

Haydon, T., Stevens, D., \& Leko, M. L. (2018). Teacher stress: sources, effects, and protective factors. Journal of Special Education Leadership, 31(2), 99-108.

Ho, C.-L., \& Au, W.-T. (2006). Teaching satisfaction scale. Measuring job satisfaction of teachers. Educational and Psychological Measurement, 66(1), 172-185.

Hwang, Y.-S., Bartlett, B., Greben, M., \& Hand, K. (2017). A systematic review of mindfulness interventions for in-service teachers: a tool to enhance teacher wellbeing and performance. Teaching and Teacher Education, 64, 26-42.

Ingersoll, R. (2001). Teacher turnover and teacher shortage. American Educational Research Journal, 38(3), 499-534.

Janssen, F., de Hullu, E., \& Tigelaar, D. (2008). Positive experiences as input for reflection by student teachers. Teachers and Teaching, 14(2), 115-127.

Judge, T. A., Thoresen, C. J., Bono, J. E., \& Patton, G. K. (2001). The job satisfaction-job performance relationship: A qualitative and quantitative review. Psychol Bull, 127(3), 376-407.

Keeney, J. (2009). Savouring success: effects of basking and acknowledgement of others in response to achievement. Unpublished master's thesis. Michigan State University, East Lansing, MI. 
King, L. A. (2001). The health benefits of writing about life goals. Personality and Social Psychology Bulletin, 111(4), 670-675.

Klassen, R. M., Yelderen, S., \& Durksen, T. L. (2013). Measuring teacher engagement: development of the engaged teachers scale (ETS). Frontline Learn Res, 2, 22-52.

Klusmann, U., Richter, D., \& Lüdtke, O. (2016). Teachers' emotional exhaustion is negatively related to students' achievement: evidence from a large-scale assessment study. Journal of Educational Psychology, 108(8), 1193-1203.

Kyriacou, C. (2001). Teacher stress: directions for future research. Educational Review, 53, $27-35$.

Liossis, P. L., Shochet, I. M., Millear, P. M., \& Biggs, H. (2009). The promoting adult resilience (PAR) program: the effectiveness of the second, shorter pilot of a workplace prevention program. Behaviour Change, 26(2), 97-112.

Luthans, F., Avey, J. B., \& Patera, J. L. (2008). Experimental analysis of a web-based intervention to develop positive psychological capital. Academy of Management Learning \& Education, 7(2), 209-221.

Luthans, F., Avey, J. B., Avolio, B. J., \& Peterson, S. J. (2010). The development and resulting performance impact of positive psychological capital. Human Resource Development Quarterly, 21(4), 41-67.

Lyubomirsky, S., \& Layous, K. (2013). How do simple positive activities increase well-being? Current Directions in Psychological Science, 22(1), 57-62.

Lyubomirsky, S., Sheldon, K. M., \& Schkade, D. (2005). Pursuing happiness: the architecture of sustainable change. Review of General Psychology, 9, 111-131.

Lyubomirsky, S., Dickerhoof, R., Boehm, J. K., \& Sheldon, K. M. (2011). Becoming happier takes both a will and a proper way: an experimental longitudinal intervention to boost well-being. Emotion, 11, 391-402.

Maslach, C., Jackson, S. E., \& Leiter, M. P. (1996). Maslach burnout inventory. Palo Alto: Consulting Psychologists Press.

McCallum, F., Price, D., Graham, A., \& Morrison, A. E. (2017). Teacher wellbeing: a review of the literature. The Association of Independent Schools of New South Wales Limited. Sydney, NSW.

McCullough, M. M. (2015). Improving elementary teachers' well-being through a strengths-based intervention: A multiple baseline single-case design. (Doctoral Dissertation), http://scholarcommons.usf.edu/etd/5990.

McIntyre, S. E., McIntyre, T. M., \& Francis, D. J. (2017). Implications of an occupational health perspective for educator stress research, practice, and policy. In T. M. McIntyre, S. E. McIntyre, \& D. J. Francis, Educator Stress (pp. 485-505). Springer, Cham.

Millear, P., Liossis, P., Shochet, I. M., Biggs, H., \& Donald, M. (2008). Being on PAR: outcomes of a pilot trial to improve mental health and wellbeing in the workplace with the promoting adult resilience (PAR) program. Behaviour Change, 25(4), 215-228.

Mitchell, J., Stanimirovic, R., Klein, B., \& Vella-Brodrick, D. A. (2009). A randomised controlled trial of a self-guided internet intervention promoting wellbeing. Computers in Human Behaviour, 25, 749-760.

Montgomery, C., \& Rupp, A. A. (2005). A meta-analysis for exploring the diverse causes and effects of stress in teachers. Canadian Journal of Education, 28(3), 458-486.

Necsoi, D.-V. (2018). Overview on teacher stress management interventions. Journal Plus Education, 11, $255-263$.

Nevill, D. S. (2014). Positive interventions: Developing a theoretical model to guide their development and use Master of Applied Positive Psychology (MAPP) Capstone Projects, 74. Retrieved from http://repository.upenn.edu/mapp_capstone/74

Ouweneel, E., Le Blanc, P. M., \& Schaufeli, W. B. (2013). Do-it-yourself: an online positive psychology intervention to promote positive emotions, self-efficacy, and engagement at work. Career Dev Int, 18(2), 173-195.

Page, K. M., \& Vella-Brodrick, D. A. (2013). The working for wellness program: RCT of an employee wellbeing intervention. J Happiness Stud, 14(3), 1007-1031.

Parks, A. C., \& Schueller, S. M. (2014). The Wiley-Blackwell handbook of positive psychological interventions. Chichester: Wiley Blackwell.

Parks, A. C., \& Titova, L. (2016). Positive psychological interventions: An overview. In A. M. Wood \& J. Johnson (Eds.), Wiley-Blackwell handbook of positive clinical psychology (pp. 307-320). Chichester: Wiley Blackwell.

Parks, A. C., Williams, A. L., Tugade, M. M., Hokes, K. E., Honomichl, R. D., \& Zilca, R. D. (2018). Testing a scalable web and smartphone-based intervention to improve depression, anxiety, and resilience: a randomized controlled trial. International Journal of Wellbeing, 8(2), 22-67.

Rahm, T., \& Heise, E. (2019). Teaching happiness to teachers - Development and evaluation of a training in subjective well-being. Frontiers in Psychology. https://doi.org/10.3389/fpsyg.2019.02703.

Schueller, S. M. (2011). To each his own well-being boosting intervention: using preference to guide selection. Journal of Positive Psychology, 6, 300-313.

Schueller, S. M. (2014). Person-activity fit in positive psychological interventions. In A. C. Parks \& S. M. Schueller (Eds.), The Wiley-Blackwell handbook of positive psychological interventions (pp. 385-402). Chichester: Wiley Blackwell. 
Seligman, M. E. P., \& Adler, A. (2019). Positive education. In J. F. Helliwell, R. Layard, \& J. Sachs (Eds.), Global happiness and wellbeing policy report (pp. 53-72). New York: Global Happiness Council.

Seligman, M. E. P., Steen, T. A., Park, N., \& Peterson, C. (2005). Positive psychology progress: Empirical validation of interventions. American Psychologist, 60(5), 410-421.

Shen, B., McCaughtry, N., Martin, J., Garn, A., Kulik, N., \& Fahlman, M. (2015). The relationship between teacher burnout and student motivation. British Journal of Educational Psychology, 85(4), 519-532.

Sin, N. L., \& Lyubomirsky, S. (2009). Enhancing well-being and alleviating depressive symptoms with positive psychology interventions: a practice-friendly meta-analysis. Journal of Clinical Psychology, 65(5), 467-487.

Walton, G. M. (2014). The new science of wise psychological interventions. Current Directions in Psychological Science, 23(1), 73-82.

Waters, L., \& Loton, D. (2019). SERACH: a meta-framework and review of field of positive education. International Journal of Applied Positive Psychology, 4(1), 1-46.

Wilson, V. (2002). Feeling the strain. An overview of the literature on teacher stress. York: Reports Express.

Yelderen, S., Durksen, T. L., \& Klassen, R. M. (2018). An international validation of the engaged teachers scale. Teachers and Teaching, 24(6), 673-689.

Publisher's Note Springer Nature remains neutral with regard to jurisdictional claims in published maps and institutional affiliations. 